NBER WORKING PAPER SERIES

\title{
WELFARE COSTS OF IDIOSYNCRATIC AND AGGREGATE CONSUMPTION SHOCKS
}

\author{
George M. Constantinides
}

Working Paper 29009

http://www.nber.org/papers/w29009

\author{
NATIONAL BUREAU OF ECONOMIC RESEARCH \\ 1050 Massachusetts Avenue \\ Cambridge, MA 02138 \\ July 2021
}

I thank John Cochrane, Ian Dew-Becker, Darrell Duffie, Anisha Ghosh, Fatih Guvenen, Greg Kaplan, Robert Lucas, Rajnish Mehra, and Constantine Yannelis for their helpful advice and feedback. I thank Tianshu Lyu and, in particular, Michael Yip for feedback and excellent research assistance. I received financial support from the Center for Research in Security Prices, the University of Chicago. I have no conflicts of interest to disclose. The views expressed herein are those of the author and do not necessarily reflect the views of the National Bureau of Economic Research.

The author has disclosed additional relationships of potential relevance for this research. Further information is available online at http://www.nber.org/papers/w29009.ack

NBER working papers are circulated for discussion and comment purposes. They have not been peer-reviewed or been subject to the review by the NBER Board of Directors that accompanies official NBER publications.

(C) 2021 by George M. Constantinides. All rights reserved. Short sections of text, not to exceed two paragraphs, may be quoted without explicit permission provided that full credit, including $\odot$ notice, is given to the source. 
Welfare Costs of Idiosyncratic and Aggregate Consumption Shocks

George M. Constantinides

NBER Working Paper No. 29009

July 2021

JEL No. D31,D52,E2,E21,E24,E32,E44,G01,G12,J6

\begin{abstract}
$\underline{\text { ABSTRACT }}$
I estimate welfare benefits of eliminating idiosyncratic consumption shocks unrelated to the business cycle as $47.3 \%$ of household utility and benefits of eliminating idiosyncratic shocks related to the business cycle as $3.4 \%$ of utility. Estimates of the former substantially exceed earlier ones because I distinguish between idiosyncratic shocks related/unrelated to the business cycle, estimate the negative skewness of shocks, target moments of idiosyncratic shocks from household-level CEX data, and target market moments. Benefits of eliminating aggregate shocks are $7.7 \%$ of utility. Policy should focus on insuring idiosyncratic shocks unrelated to the business cycle, such as the death of a household's prime wage earner and job layoffs not necessarily related to recessions.
\end{abstract}

George M. Constantinides

The University of Chicago

Booth School of Business

5807 South Woodlawn Avenue

Chicago, IL 60637

and NBER

gmc@ChicagoBooth.edu 


\section{Introduction}

The contribution of this paper is to address the welfare benefits of eliminating shocks to household consumption growth in a novel way and report welfare benefits substantially higher than benefits earlier reported in the literature. I report that the benefits of eliminating all idiosyncratic shocks are $52.3 \%$ of the utility of a member of a household. This can be more concretely characterized by saying that the welfare gain is equivalent to that associated with an increase in the path of a consumer's level consumption by $52.3 \%$, state by state, date by date. The welfare benefits of eliminating idiosyncratic shocks unrelated to the business cycle are $47.3 \%$ of utility while the welfare benefits of eliminating idiosyncratic shocks related to the business cycle are $3.4 \%$ of utility. The major implication is that the policy debate should focus on insuring idiosyncratic shocks unrelated to the business cycle, such as the death of a household's prime wage earner and job layoffs not necessarily related to recessions.

There are several reasons why my welfare estimates are substantially higher than earlier estimates. First, my model distinguishes between idiosyncratic shocks related to the business cycle and shocks unrelated to the business cycle, unlike the earlier literature which does not draw such distinction. For example, the death of the prime wage-earner in the household is unrelated to the business cycle while the loss of employment is more likely to occur during a recession. Second, I recognize that idiosyncratic consumption shocks are highly negatively skewed. The welfare implications of highly negatively skewed idiosyncratic shocks are magnified by the fact that marginal utility is high when consumption is low. Third, the calibration of the welfare benefits is based on parameters obtained by estimating the model using household-level consumption data from the Consumer Expenditure Survey (CEX) and explicitly targeting moments of idiosyncratic consumption. Fourth, I assume that households are responsive to long-run risks by having EpsteinZin preferences. Finally, I incorporate information from the market by targeting the moments of the interest rate, asset prices, and dividends in the estimation, in addition to the moments of aggregate and household consumption growth.

I report that the welfare benefits of eliminating all shocks to aggregate consumption growth around trend are $7.7 \%$ of utility. While small compared to the benefits of eliminating idiosyncratic shocks, they are higher than most estimates in the literature. There is a caveat to the welfare benefits of eliminating shocks to aggregate consumption growth reported in this paper and in the 
cited literature. The results are in the context of exchange economies that ignore the disruption in production during recessions and, therefore, underestimate the welfare costs.

Literature Review. I build on a large literature on the welfare costs of fluctuations in consumption originated by Lucas (2003) in his presidential address to the American Economic Association in which he argues that the cost of business cycle fluctuations is negligible:

[A] single consumer is magically relieved of all consumption variability about trend. How much average consumption would he be willing to give up in return? About one-half of one-tenth of a percent, I calculate."

The ensuing literature addresses Lucas’ (2003) key assumptions in reaching this conclusion. The first is the existence of a representative household, an assumption that is justified if there is complete consumption insurance of idiosyncratic shocks. The second assumption is that aggregate consumption shocks are serially uncorrelated. The third assumption is that preferences are time separable and isoelastic.

The paper draws on several strands of the literature. It draws on the empirical evidence by Attanasio and Davis (1996), Blundell, Pistaferri, and Preston (2008), Brav, Constantinides, and Geczy (2002), and Cochrane (1991) that households face a substantial amount of uninsurable idiosyncratic labor income risk and consumption insurance is incomplete. Davis and von Wachter (2011), Jacobson, LaLonde, and Sullivan (1993), Kletzer and Fairlie (2003), and Ruhm (1991) show that people who are laid off in recessions can see average declines in lifetime income between $9 \%$ and $30 \%$.

It draws on the literature that examines the welfare costs of business cycles in economies with idiosyncratic consumption shocks and incomplete consumption insurance. Some researchers find that the welfare costs of business cycles are small. Atkeson and Phelan (1994) show that the potential welfare gains from eliminating the correlation in households' income risk in a given environment is smaller when markets are incomplete than when markets are complete and argue that the potential welfare gains from a countercyclical policy are essentially zero. Berger et al. (2019) show in calibration that welfare may increase by at least $1 \%$ of lifetime consumption when the central bank's policy rule responds to the layoff rate instead of purely targeting inflation. Imrohoroglu (1989) finds that the welfare cost of business cycles, as a percentage of consumption, is about 0.08-1.5\%. Krusell, Mukoyama, Şahin, and Smith (2009) and Krusell and Smith (1999) 
find that the overall cost of business cycles is small but that there are large differences across household groups. Others find that the welfare costs of business cycles are large. Beaudry and Pages (2001) and Storesletten, Telmer, and Yaron (2001) report higher estimates of the cost but only for households that have no wealth. Krebs (2007) finds a higher cost of $7.5 \%$ for all households under the assumption that earnings shocks are permanent.

The paper relates to the literature by Dolmas (1998), Epaulard and Pommeret (2003), Obstfeld (1994), Otrok (2001), Pemberton (1996), and Tallarini (2000) that relaxes the assumption that preferences are time separable and isoelastic. The assumption that aggregate consumption is serially uncorrelated is relaxed in many of these papers and is highlighted by Reis (2009).

The paper relates to Alvarez and Jermann (2004) and Ghosh, Julliard, and Stutzer (2019) who extract estimates of the cost of aggregate consumption fluctuations from the prices of financial assets. Ghosh, Julliard, and Stutzer (2019) report costs as high as 3\%. Barro (2009) finds that the welfare cost of rare disasters is $20 \%$ of GDP in a model in which the one-year drop in aggregate consumption is calibrated to match the observed average four-year drop in aggregate consumption. The welfare cost is substantially lower if the one-year drop in aggregate consumption is calibrated to match the observed average one-year drop in aggregate consumption.

The paper also draws on the literature that highlights the importance of idiosyncratic shocks in the pricing of financial assets by Brav, Constantinides, and Geczy (2002), Constantinides and Duffie (1996), Constantinides and Ghosh (2017), Huggett (1993), Mankiw (1986), and Storesletten, Telmer, and Yaron (2004). Finally, the paper draws on the literature that highlights the importance of idiosyncratic consumption shocks in macroeconomics, for example, Kaplan, Moll, and Violante (2018), Kaplan and Violante (2014), and Krusell and Smith (1998).

The paper is organized as follows. In Section II, I describe the economy, data, and estimation of the model. In Section III, I present the welfare benefits of eliminating various shocks to consumption growth. I conclude in Section IV. Proofs are relegated to the online appendices. 


\section{The Economy, Data, and Estimation}

\section{II.1 The economy}

I model an exchange economy. As in Bansal and Yaron (1984), the conditional expectation of aggregate consumption growth and dividend growth depend on the state of the business cycle. This feature provides a framework for addressing the welfare benefits of smoothing fluctuations of aggregate consumption growth along the business cycle and around trend. As in Constantinides and Duffie (1996) and Constantinides and Ghosh (2017), consumers are heterogeneous with uninsurable and persistent idiosyncratic consumption shocks. This feature allows me to compare the welfare benefits of smoothing fluctuations of aggregate consumption growth to the welfare benefits of smoothing idiosyncratic shocks to consumption growth that are either dependent on the business cycle or independent of the business cycle. I find that the welfare benefits of smoothing idiosyncratic shocks that are independent of the business cycle are far greater than the welfare benefits of smoothing aggregate consumption shocks.

Households have identical recursive preferences as in Epstein and Zin (1989) and Weil (1990):

$$
U_{i t}=\left\{(1-\delta)\left(C_{i t}\right)^{1-1 / \psi}+\delta\left(E_{t}\left[\left(U_{i, t+1}\right)^{1-\gamma}\right]\right)^{\frac{1-1 / \psi}{1-\gamma}}\right\}^{1 /(1-1 / \psi)},
$$

where $\delta$ is the subjective discount factor, $\gamma$ is the relative risk aversion coefficient (RRA), and $\psi$ is the elasticity of intertemporal substitution (EIS). These preferences capture long run risks in consumption and dividends.

In the welfare analysis, I set the EIS to be equal to one, $\psi=1$, because I estimate the EIS to be one. The model fit is insensitive as to whether the EIS is greater or lower than one and sidesteps the controversy on this issue. Furthermore, I show in the online Appendix B.2, that the utility is insensitive to small deviations of the EIS from one. With $\psi=1$, household preferences simplify as

$$
U_{i t}=C_{i t}^{1-\delta}\left\{E_{t}\left[\left(U_{i, t+1}\right)^{1-\gamma}\right]\right\}^{\frac{\delta}{1-\gamma}} .
$$


Next, I describe the processes of post-trade consumption. Alternatively, these processes may be viewed as the processes of aggregate and household income in a no-trade equilibrium as in Constantinides and Duffie (1996, Proposition 1). Aggregate consumption at date $t$ is denoted by $C_{t}$, $\log$ consumption by $c_{t} \equiv \log \left(C_{t}\right)$, and consumption growth by $\Delta c_{t+1} \equiv C_{t+1}-c_{t}$. I assume that the process of aggregate consumption growth is

$$
\Delta c_{t+1}=\mu_{a}+\beta_{a}\left(x_{t}-\bar{x}\right)+\sigma_{a} \varepsilon_{a, t+1},
$$

where $\varepsilon_{a t} \sim N(0,1)$ and i.i.d., $x_{t}$ is a state variable that tracks the business cycle, $\bar{x}$ is its unconditional mean, $\mu_{a}$ is the unconditional mean of consumption growth, and $\sigma_{a}$ is the conditional volatility of consumption growth. The term $\beta_{a}\left(x_{t}-\bar{x}\right)$ captures the dependence of consumption growth on the business cycle and is a persistent shock. The term $\sigma_{a} \varepsilon_{a, t+1}$ captures transient shocks. This specification of aggregate consumption growth is consistent with empirical evidence reported by Reis (2009, Table 2) and differs from the specification by Lucas $(1987,2003)$ who assumes that the level of aggregate consumption is serially uncorrelated.

Some properties of idiosyncratic income shocks are well known. People who are laid off in recessions can see average declines in lifetime income between 9\% and 30\%. Furthermore, Guvenen, Karahan, Ozkan, and Song (2016) report that, in a given year, most individuals experience small earnings changes and a small number experience large changes. I do not model idiosyncratic income shocks and do not contribute to the extensive literature on the extent to which idiosyncratic income shocks are transmitted to consumption. Instead, I directly model idiosyncratic consumption shocks.

The incidence of an idiosyncratic consumption shock on a particular household is infrequent but its size is big. I model these shocks as permanent. ${ }^{1}$ Households are sensitive to permanent shocks because these are long run risks captured with the assumed Epstein-Zin

\footnotetext{
${ }^{1}$ Ideally, I should be modelling and estimating both transient and permanent idiosyncratic consumption shocks because the omission of transient shocks may bias the welfare implications of permanent shocks. This cannot be accomplished with CEX data because CEX is a cross-sectional data base that provides consumption data on each household for only five consecutive quarters of which only the last four quarters are reliable. Since 1999, the Panel Study of Income Dynamics (PSID) has been collecting data on transportation, health care, education, utilities, and childcare expenditures, in addition to data collected earlier on food and housing expenditures. Being a longitudinal data base, it may be used to estimate both transient and permanent idiosyncratic consumption shocks.
} 
preferences. There is a continuum of households. Consumption at date $t$ of household $i$ is denoted by $C_{i t}$, $\log$ consumption by $c_{i t} \equiv \log \left(C_{i t}\right)$, and consumption growth by $\Delta c_{i, t+1} \equiv c_{i, t+1}-c_{i t}$. I assume that idiosyncratic shocks to consumption growth are drawn from the same distribution across households, an assumption that needs to be relaxed in future research.

I distinguish between idiosyncratic shocks to consumption growth that are related to the business cycle and shocks that are unrelated to the business cycle. To this end, I model idiosyncratic consumption growth as the sum of three terms, as

$$
\Delta c_{i, t+1}=\Delta c_{t+1}+\left(j_{i, t+1}^{1 / 2} \sigma \eta_{i, t+1}-j_{i, t+1} \sigma^{2} / 2\right)+\left(\hat{j}_{i, t+1}^{1 / 2} \hat{\sigma}_{i, t+1}-\hat{j}_{i, t+1} \hat{\sigma}^{2} / 2\right),
$$

where the random variables $\eta_{i, s} \sim N(0,1)$ and $\hat{\eta}_{i, s} \sim N(0,1)$ are i.i.d. and independent of all primitive random variables in the economy. The second and third terms represent permanent shocks to idiosyncratic consumption growth and this approximates the property that I wish to impart to the model that the shocks are persistent, consistent with empirical evidence. As shown in Constantinides and Duffie (1996), the joint assumptions that the number of households is infinite and the consumption shocks are symmetric across households allow me to apply the law of large numbers and show that the identity $\sum_{i} C_{i t}=C_{t}$ is respected because $\sum_{i} C_{i t}=E\left[C_{i t}\right]=C_{t}$.

If the terms $j_{i, t+1}$ and $\hat{j}_{i, t+1}$ were constant, then the idiosyncratic shocks $\Delta c_{i, t+1}-\Delta c_{t+1}$ would be normally distributed and would miss the negative skewness observed in the data. The negative skewness is important because marginal utility is high upon the incidence of a negative shock and these shocks have a bigger effect on welfare than positive idiosyncratic shocks do. To this end, I assume that the random variable $j_{i, s}$ has a Poisson distribution with $\operatorname{prob}\left(j_{i, t}=n\right)=e^{-\omega_{t}} \omega_{t}^{n} / n !$, $n=0,1, \ldots, \infty, E\left(j_{i, t}\right)=\operatorname{var}\left(j_{i, t}\right)=\omega_{t}$, skewness $\left(j_{i, t}\right)=\omega_{t}^{-1 / 2}$, and independent of all primitive random variables in the economy. I define $x_{t} \equiv\left(e^{-\gamma(1-\gamma) \sigma^{2} / 2}-1\right) \omega_{t}$. Hereafter I refer to $\omega_{t}$ and $x_{t}$ interchangeably as the state variable because I estimate $\gamma$ to be slightly greater than one and, therefore, $\omega_{t}$ and $x_{t}$ have the same sign. Likewise, the random variable $\hat{j}_{i, t}$ has a Poisson 
distribution with $\operatorname{prob}\left(\hat{j}_{i, t}=n\right)=e^{-\hat{\omega}} \hat{\omega}^{n} / n !, \quad n=0,1, \ldots \infty, E\left(j_{i, t}\right)=\widehat{\omega}$, independent of all primitive random variables in the economy and where $\widehat{\omega}$ is a parameter.

The state variable $\omega_{t}$ has the natural interpretation as a countercyclical business cycle variable for a number of reasons. First, the variance of the idiosyncratic consumption shocks is

$$
\mu_{2}\left(\log \left(\frac{C_{i, t+1} / C_{t+1}}{C_{i, t} / C_{t}}\right) \mid \omega_{t+1}\right)=\left(\sigma^{2}+\sigma^{4} / 4\right) \omega_{t+1}+\left(\hat{\sigma}^{2}+\hat{\sigma}^{4} / 4\right) \hat{\omega}
$$

and is increasing in $\omega_{t}$. Second, the negative skewness of the idiosyncratic consumption shocks is

$$
\mu_{3}\left(\log \left(\frac{C_{i, t+1} / C_{t+1}}{C_{i, t} / C_{t}}\right) \mid \omega_{t+1}\right)=-\left(3 \sigma^{4} / 2+\sigma^{6} / 8\right) \omega_{t+1}-\left(3 \hat{\sigma}^{4} / 2+\hat{\sigma}^{6} / 8\right) \hat{\omega}
$$

and is increasing in $\omega_{t}$, consistent with Guvenen, Ozkan, and Song (2014) who find that the skewness of idiosyncratic income shocks is strongly countercyclical. Finally, both in the model and in the data the risk free rate and expected market return are increasing in $\omega_{t}$ while the pricedividend ratio of the market is decreasing in $\omega_{t}$.

I assume that $x_{t}$ follows the heteroscedastic AR(1) process

$$
x_{t+1}=(1-\rho) \bar{x}+\rho x_{t}+x_{t}^{1 / 2} \varepsilon_{x, t+1}
$$

where $\varepsilon_{x, t} \sim N\left(0, \sigma_{x}^{2}\right), \quad \bar{x}>0$, and $0<\rho<1$.

Finally, I assume that the log dividend growth of the stock market follows the process

$$
\Delta d_{t+1}=\alpha_{d}+\beta_{d} x_{t}+\sigma_{d} \varepsilon_{d, t+1}
$$

where $\varepsilon_{d, t+1} \sim N(0,1)$ is independent of all primitive random variables. The term $\beta_{d} x_{t}$ captures the dependence of dividend growth on the business cycle. 


\section{II.2 Data}

I estimate and test the model with quarterly consumption data from 1982:Q1 to 2019:Q4 and with annual consumption data from 1929 to 2019. The household-level quarterly consumption data come from the Consumer Expenditure Survey, produced by the Bureau of Labor Statistics from 1980:Q1 to the present but I use data only from 1982:Q1 and limit my empirical study to urban households as this data subset is more reliable. I do not use income data from the PSID because this requires an examination of the extent to which income shocks are transmitted to consumption, studied by Blundell, Pistaferri, and Preston (2008) and others, but outside the scope of the present study.

For each household, I proxy consumption by the sum of nondurables and services consumption (NDS), using the National Income and Product Accounts classification of NDS. Households are grouped in three tranches. The first tranche contains households that report quarterly consumption from January to March and the subsequent four quarters. The second (third) tranche contains households that report quarterly consumption from February to April (from March to May) and the subsequent four quarters. I include only the last four quarters because these are the most reliable ones. I present estimation results for the January tranche and the combined tranches. Since the quantity of interest here is relative household consumption growth, $\log \left(\frac{C_{i, t+1} / C_{t+1}}{C_{i, t} / C_{t}}\right)$, it is unnecessary to either deflate or seasonally adjust consumption. The input to the model is per capita consumption and not household consumption. Per capita consumption is household consumption, divided by the average number of family members of all households in that quarter.

I use monthly data on market prices and dividends provided by the Center for Research in Security Prices value-weighted index of all stocks on the NYSE, AMEX, and NASDAQ from 1929 to 2019. The annual nominal market return is the sum of the price at the end of the year and the uncompounded dividends over the year, divided by the price at the beginning of the year. The real market return is the nominal return, deflated by the realized growth in the consumer price index. The annual price-dividend ratio of the market is the market price at the end of the year, divided by the sum of dividends over the previous twelve months. The real dividend growth rate 
is the sum of dividends over twelve months, divided by the sum of dividends over the previous twelve months, deflated by the realized growth in the consumer price index.

The realized real quarterly risk-free rate is the quarterly nominal yield on three-month Treasury bills, deflated by the realized growth in the consumer price index. The ex-ante quarterly risk-free rate is then obtained as the fitted value from the regression of the realized real quarterly risk-free rate on the three-month nominal yield and the realized growth in the consumer price index over the previous year. Finally, the ex-ante quarterly risk-free rate at the beginning of the year is annualized to obtain the ex-ante annual risk-free rate.

\section{II.3 Estimation}

The model has fifteen parameters: the mean, $\mu_{a}$, volatility, $\sigma_{a}$, and dependence on the business cycle, $\beta_{a}$,of aggregate consumption growth; the three parameters of idiosyncratic consumption shocks, $\sigma, \hat{\sigma}$, and $\hat{\omega}$; the three parameters of the dynamics of the state variable, $\bar{x}, \sigma_{x}$, and $\rho$; the three parameters governing the dynamics of aggregate dividend growth, $\alpha_{d}, \beta_{d}$, and $\sigma_{d}$; and the three preference parameters, the subjective discount factor, $\delta$, the relative risk aversion coefficient (RRA), $\gamma$, and the elasticity of intertemporal substitution (EIS), $\psi$.

I estimate the model with GMM at the quarterly frequency from 1982:Q1 to 2019:Q4 to match the following eighteen moments: the mean, variance, and autocorrelation of aggregate consumption growth, dividend growth, risk free rate, market return, and price-dividend ratio; and the mean, variance, and third central moment of the cross-sectional distribution of household consumption growth relative to aggregate consumption growth. These moments are presented in the online Appendix A. The weights of the weighting matrix are chosen to provide the best overall fit.

I present the estimation results for the January tranche of household consumption in Table 1. The model fits well the moments of the risk-free rate. It fits well the mean and autocorrelation of the market return and, therefore, the equity premium, but the volatility of the market return is double the volatility observed in the data. The model fits well the moments of the price-dividend ratio, a feat that challenges many models. It matches well the mean and volatility of household 
consumption growth but not its autocorrelation. It matches well the volatility of dividend growth but not the mean and autocorrelation. It also matches well the moments of the cross-sectional distribution of household consumption growth. The estimated risk aversion is about one, substantially lower than the risk aversion required in many models and consistent with the estimate of about one by Chetty (2006). Nevertheless, the model generates the observed equity premium because of the large idiosyncratic shocks. The estimated EIS is one and evades the controversy as to whether it is above or below one. It is also much lower than the EIS required in some earlier models to address the moments of financial variables. The negative estimate of $\beta_{d}$ reinforces the interpretation of $x_{t}$ as a countercyclical business cycle variable.

\section{[Table 1 here]}

As a robustness test, I re-estimate the model by expanding the pool of households to include all three tranches. For example, for the first quarter, the January tranche provides household consumption growth from January to March; the February tranche provides household consumption growth from February to April; and the lagged March tranche provides household consumption growth from December to February. The estimation results are extremely close to the results for the January tranche and are reported in the online Appendix C.

As a further robustness test, I re-estimate the model at the annual frequency over the period from 1929 to 2019. Given the lack of household-level data over the full period, I do not target the moments of the cross-sectional distribution of household consumption growth relative to aggregate consumption growth. The GMM system consists of 15 moment restrictions in 15 parameters. The estimation results are reported in Table 2. A big difference is that the estimated risk aversion is 8.59 which is much greater than the risk aversion of one estimated at the quarterly frequency. As at the quarterly frequency, the model fits well the moments of the risk-free rate. It fits well the mean, variance, and autocorrelation of the market return. Thus it fits better the variance of the market return than the model at the quarterly frequency. The model fits well the moments of the price-dividend ratio. It matches well the mean and volatility of household consumption growth but not its autocorrelation. Finally, it matches well the mean and volatility of dividend growth but not the autocorrelation. The estimated EIS is one, same as the estimate at the quarterly frequency. The autocorrelation of the state variable is 0.818 which implies that the half-life of the state variable is 3.45 years, consistent with the interpretation of the state variable as a business cycle variable. 
[Table 2 here]

\section{Welfare Benefits of Eliminating Shocks to Consumption Growth}

\section{III.1 Welfare benefits of eliminating all idiosyncratic shocks}

In the online Appendix B.1, I prove that, in the benchmark economy with $\psi=1$, household utility has the functional form

$$
U_{i t}^{\mathrm{BENCH}}=C_{i, t} e^{h+k_{t}}
$$

and derive the values of the parameters $h$ and $k$. In the online Appendix B.2, I prove that household utility is approximately given by equation (9) and the values of the parameters $h$ and $k$ are the same even when $\psi \neq 1$.

In the online Appendix B.3, I calculate the utility $U_{i t}^{\text {ZEROID }}$ in the economy in which all idiosyncratic consumption shocks are eliminated, by setting $\sigma=\hat{\sigma}=0$ in equation (4). The ratio of the utility in this economy to the utility in the benchmark economy is

$$
U_{i t}^{\text {ZEROID }} / U_{i t}^{\text {BENCH }}=\exp \left(\frac{-\hat{x}-\{(1-\gamma) k+1\}(1-\rho) \bar{x}+(1-\gamma) \beta_{a} \bar{x}}{(1-\gamma)\left(\delta^{-1}-1\right)}-k x_{t}\right) .
$$

Since the assumed preferences are homothetic, the reported percentage benefits apply to all households, irrespective of their level of wealth, since I assume that the idiosyncratic shocks are drawn from the same distribution across households.

In the third column of Table 3, I report for the January tranche the welfare gain in percent,

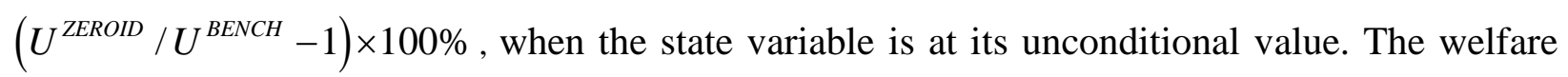
benefit in terms of utility is $52.3 \%$ and is large. Since consumption is proportional to utility, the welfare benefit in terms of consumption is $52.3 \%$ as well. In parentheses, I report the welfare gain when the state variable is set at the unconditional value plus or minus one standard error. In curly brackets, I report the welfare gain when the volatility of the idiosyncratic shocks that are related 
to the business cycle is set at the point estimate plus or minus one standard error. In square brackets, I report the welfare gain when the volatility of the idiosyncratic shocks that are unrelated to the cycle is set at the point estimate plus or minus one standard error. In the fourth column of Table 3, I report the corresponding results for the combined tranches. The results are very similar.

[Insert Table 3 here]

It is well known in the literature that the welfare gain in eliminating idiosyncratic income shocks can be large. At the low end, Imrohoroglu (1989) finds that the welfare cost of business cycles, as a percentage of consumption, is about 0.08-1.5\%. At the high end, Beaudry and Pages (2001) estimate the cost as high as 4.4\%; Storesletten, Telmer, and Yaron (2001) report that an unborn agent is better off by 5.09\% and that, on average, the population is better off by $1.03 \%$; and Krebs (2007) reports the highest cost at 7.5\%. By contrast, my estimate of $52.3 \%$ is substantially higher than earlier estimates for several reasons. First, I allow for negative skewness in the shocks. Second, I estimate the skewness by targeting the moments of idiosyncratic consumption growth. Finally, I estimate the model by targeting the moments of the interest rate, asset prices, and dividends, in addition to the moments of aggregate and household consumption.

In the fifth column of Table 3, I report the corresponding results when the parameters are estimated at the annual frequency. The welfare benefit is $6.18 \%$, substantial but much smaller than the benefit of 52.3\% reported when the parameters are estimated at the quarterly frequency. The reason is that the moments of the household consumption growth are not targeted at the annual estimation because these moments are unavailable over the full period from 1929 to 2019. I consider the estimate of $52.3 \%$ as a more reliable estimate.

\section{III.2 Welfare benefits of eliminating idiosyncratic shocks unrelated to the business cycle}

I eliminate only the idiosyncratic shocks to consumption growth that are unrelated to the business cycle. The utility ratio is calculated in the online Appendix B.3 as

$$
U_{i t}^{\text {ZEROUNRELATEDID }} / U_{i t}^{\text {BENCH }}=e^{-\widehat{\chi /} /(1-\gamma)\left(\delta^{-1}-1\right)} .
$$


The results are shown in Table 3. The welfare gain is $47.3 \%$ when the parameters are estimated from the January tranche and $45.9 \%$ when the parameters are estimated from the combined tranches. The welfare gain is large.

I also calculate the utility $U_{i t}^{\text {ZERORELATEDID }}$ in the economy in which idiosyncratic consumption shocks related to the business cycle are eliminated. The utility ratio is

$$
U_{i t}^{\text {ZERORELATEDID }} / U_{i t}^{\text {BENCH }}=\exp \left(\frac{(1-\gamma) \beta_{a} \bar{x}-\{(1-\gamma) k+1\}(1-\rho) \bar{x}}{(1-\gamma)\left(\delta^{-1}-1\right)}-k x_{t}\right) .
$$

The results are shown in Table 4. The welfare gain is 3.4\% when the parameters are estimated from the January tranche and 2.9\% when the parameters are estimated from the combined tranches. The welfare gain is significant but substantially smaller than the gain from eliminating shocks unrelated to the business cycle. The major implication of these results is that policy should be directed towards insuring idiosyncratic shocks unrelated to the business cycle.

I gain further insights by examining the contribution of idiosyncratic shocks to the variance and skewness of household consumption growth. In equation (5), the variance of the idiosyncratic shocks is the sum of two components contributed by shocks related and unrelated to the business cycle, respectively. In equation (6), the skewness is the sum of two components contributed by shocks related and unrelated to the business cycle, respectively. In Table 4, I present this decomposition with parameters estimated at both the quarterly and annual frequencies. I present results when the state variable is set at its unconditional value and, in brackets, when the state variable is set at the unconditional value plus or minus one standard error. I also present the variance of aggregate consumption shocks as well. The contribution of idiosyncratic shocks unrelated to the business cycle to the variance and skewness of household consumption growth is an order of magnitude higher than the contribution of shocks related to the business cycle and several orders of magnitude higher than the contribution of aggregate shocks.

[Insert Table 4 here] 


\section{III.3 Welfare benefits of eliminating shocks to aggregate consumption growth}

I eliminating fluctuations of aggregate consumption growth around the business cycle by setting $\beta_{a}=0$. The utility ratio is calculated in the online Appendix B4 as

$$
\begin{aligned}
& U_{i t}^{\text {NOBUSAGG }} / U_{i t}^{\text {BENCH }} \\
& =\exp \left\{\frac{\beta_{a} \bar{x}}{\delta^{-1}-1}+\frac{\left(\rho+\sigma_{x}^{2}-\delta^{-1}\right)}{(1-\gamma) \sigma_{x}^{2}}\left[\sqrt{1-\frac{2 \sigma_{x}^{2}\left(\rho+\sigma_{x}^{2} / 2\right)}{\left(\rho+\sigma_{x}^{2}-\delta^{-1}\right)^{2}}}-\sqrt{1-\frac{2 \sigma_{x}^{2}\left((1-\gamma) \beta_{a}+\rho+\sigma_{x}^{2} / 2\right)}{\left(\rho+\sigma_{x}^{2}-\delta^{-1}\right)^{2}}}\right] x_{t}\right\} .
\end{aligned}
$$

The results are presented in Table 3 . The welfare gain is practically zero, irrespective of whether the parameters are estimated at the quarterly or annual frequencies.

Finally, I eliminate all fluctuations of aggregate consumption growth around trend by setting $\beta_{a}=\sigma_{a}=0$. The utility ratio is calculated in the online Appendix B4 as

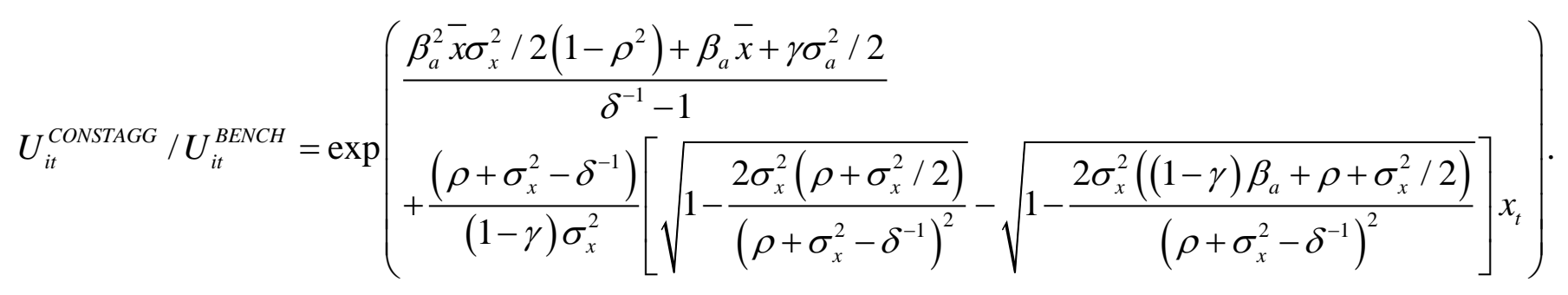

The results are presented in Table 3. The welfare gain is practically zero when the parameters are estimated at the quarterly frequency but $7.7 \%$ when the parameters are estimated at the annual frequency. I place greater weight on the estimate at the annual frequency than on the estimate at the quarterly frequency because the annual estimation covers a much longer time period of aggregate consumption than the quarterly estimation.

The welfare benefits of eliminating shocks to aggregate consumption growth are higher than the corresponding $0.5 \%$ benefits reported by Lucas (2003) who eliminates shocks to the aggregate consumption level while I eliminate shocks to aggregate consumption growth. They are also higher than the $0.5 \%-5 \%$ gain reported by Reis (2009) and the 3\% gain reported by Ghosh, Julliard, and Stutzer (2019). The main take-away is that the welfare benefits of eliminating shocks 
to aggregate consumption growth are significant but substantially lower than the welfare benefits of eliminating idiosyncratic shocks.

\section{Concluding Remarks}

The paper draws attention to the need for policies to minimize the welfare costs associated with idiosyncratic shocks to household income and consumption growth. I find that the benefits of eliminating idiosyncratic shocks to consumption unrelated to the business cycle are $47.3 \%$ of the utility of a member of a household and the benefits of eliminating idiosyncratic shocks to consumption related to the business cycle are 3.4\% of utility. The estimate of the benefits of eliminating idiosyncratic shocks to consumption unrelated to the business cycle is substantially higher than earlier estimates. Finally, the welfare benefits of eliminating shocks to aggregate consumption growth are important but substantially lower than the welfare benefits of eliminating idiosyncratic shocks unrelated to the business cycle. The main implication is that policy should focus on insuring idiosyncratic shocks unrelated to the business cycle, such as the death of the prime wage earner in the family and job layoffs not necessarily related to recessions.

The main drivers of these results are that I distinguish between idiosyncratic shocks related to the business cycle and shocks unrelated to the business cycle, recognize that idiosyncratic shocks are highly negatively skewed, calibrate the welfare benefits based on parameters obtained by estimating the model using household-level consumption data from the Consumer Expenditure Survey and explicitly targeting moments of household consumption, assume that households are responsive to long-run risks, and incorporate information from the market by targeting the moments of the interest rate, stock prices, and dividends in the estimation, in addition to the moments of aggregate and idiosyncratic consumption growth.

Since I assume that preferences are homothetic and idiosyncratic shocks to consumption growth are drawn from the same distribution across households, the reported percentage benefits apply to all households, irrespective of their level of wealth. This assumption needs to be relaxed in future research. Furthermore, households are heterogeneous in ways beyond the level of their wealth, such as aversion to risk, employment category, borrowing constraints, home production, labor supply of other members of the household, ability to substitute leisure for consumption, and 
geographical location. It is an open question as to how recognition of these additional heterogeneities modifies the welfare costs associated with idiosyncratic shocks. 


\section{References}

Alvarez, Fernando and Urban J. Jermann, 2004, "Using Asset Prices to Measure the Cost of Business Cycles,” Journal of Political Economy 112: 1223-1256.

Atkeson, Andrew and Christopher Phelan, 1994, "Reconsidering the Costs of Business Cycles with Incomplete Markets,” In NBER Macroeconomics Annual 1994, edited by Stanley Fisher and Julio J. Rotemberg. MIT Press.

Attanasio, Orazio P. and Steven J. Davis, 1996, “Relative Wage Movements and the Distribution of Consumption,” Journal of Political Economy 104: 1227-1262.

Bansal, Ravi and Amir Yaron, 2004, "Risks for the Long Run: A Potential Resolution of Asset Pricing Puzzles,” Journal of Finance 59: 1481-1509.

Barro, Robert J., 2009, “Rare Disasters, Asset Prices, and Welfare Costs,” American Economic Review 99: 243-264.

Beaudry, Paul and Carmen Pages, 2001, “The Cost of Business Cycles and the Stabilization Value of Unemployment Insurance,” European Economic Review 45: 1545-1572.

Berger, David, Ian Dew-Becker, Lawrence D. W. Schmidt, and Yuta Takahashi, 2019, “Layoff Risk, the Welfare Cost of Business Cycles, and Monetary Policy,” working paper, Northwestern University, MIT, and NBER.

Blundell, Richard, Luigi Pistaferri, and Ian Preston, 2008, “Consumption Inequality and Partial Insurance,” American Economic Review 98: 1887-1921.

Brav, Alon, George M. Constantinides, and Christopher C. Geczy, 2002, “Asset Pricing with Heterogeneous Consumers and Limited Participation: Empirical Evidence,” Journal of Political Economy 110: 793-824.

Chetty, Raj, 2006, “A New Method of Estimating Risk Aversion,” American Economic Review 96: 1821-1834.

Cochrane, John, 1991, “A Simple Test of Consumption Insurance,” Journal of Political Economy 99: 957-976.

Constantinides, George M. and Darrell Duffie, 1996, “Asset Pricing with Heterogeneous Consumers,” Journal of Political Economy 104: 219-240. 
Constantinides, George M. and Anisha Ghosh, 2017, “Asset Pricing with Countercyclical Household Consumption Risk,” Journal of Finance 73: 415-459.

Davis, Steven J. and Till von Wachter, 2011, “Recessions and the Costs of Job Loss,” Brookings Papers on Economic Activity: 1-55.

Dolmas, Jim, 1998, "Risk Preferences and the Welfare Cost of Business Cycles," Review of Economic Dynamics 1: 646-676.

Epaulard, Anne and Aude Pommeret, 2003, "Recursive Utility, Endogenous Growth, and the Welfare Cost of Volatility,” Review of Economic Dynamics 6: 672-684.

Epstein, Larry R. and Stanley E. Zin, 1989, “Substitution, Risk Aversion, and the Temporal Behavior of Consumption and Asset Returns: A Theoretical Framework,” Econometrica 57: 937-969.

Ghosh, Anisha, Christian Julliard, and Michael Stutzer, 2019, “The Market Cost of Business Cycle Fluctuations,” working paper, London School of Economics and Magill University.

Guvenen, F., S. Ozkan, and J. Song, 2014, “The Nature of Countercyclical Income Risk,” Journal of Political Economy 122: 621-660.

Huggett, Mark, 1993, “The Risk-Free Rate in Heterogeneous-Agent Incomplete-Insurance Economies,” Journal of Economic Dynamics and Control 17: 953-969.

Imrohoroglu, Ayse, 1989, "The Cost of Business Cycles with Indivisibilities and Liquidity Constraints,” Journal of Political Economy 97: 1364-1383.

Jacobson, Louis S., Robert J. LaLonde, and Daniel G. Sullivan, 1993, "Earnings Losses of Displaced Workers,” American Economic Review 83: 685-709.

Kaplan, Greg, Benjamin Moll, and Giovanni L. Violante, 2018, “Monetary Policy according to HANK,” American Economic Review 108: 697-743.

Kaplan, Greg and Giovanni L. Violante, 2014, “A Model of the Consumption Response to Fiscal Stimulus Payments,” Econometrica 82: 1199-1239.

Kletzer, Lori G. and Robert W. Fairlie, 2003, “The Long-Term Costs of Job Displacement for Young Adult Workers,” Industrial \& Labor Relations Review 56: 682-698. 
Krebs, Tomas, 2007, "Job Displacement Risk and the Costs of Business Cycles," American Economic Review 97: 664-686.

Krusell, Per and Anthony A. Smith Jr., 1999, "On the Welfare Effects of Eliminating Business Cycles,” Review of Economic Dynamics 2: 245-272.

Krusell, Per, Toshihiko Mukoyama, Aysegu Şahin, and Anthony A. Smith Jr., 2009, "Revisiting the Welfare Effects of Eliminating Business Cycles,” Review of Economic Dynamics 12: 393-404.

Lucas, Jr., Robert E., 2003, “Macroeconomic Priorities,” American Economic Review 93: 1-14.

Lucas, Jr., Robert E., 1987, Models of Business Cycles, Oxford: Basil Blackwell.

Mankiw, Gregory N., 1986, “The Equity Premium and the Concentration of Aggregate Shocks,” Journal of Financial Economics 17: 211-219.

Obstfeld, Maurice, 1994, "Evaluating Risky Consumption Paths: The Role of Intertemporal Substitutability,” European Economic Review 38: 1471-1486.

Otrok, Christopher, 2001, "On Measuring the Welfare Cost of Business Cycles," Journal of Monetary Economics 47: 61-92.

Pemberton, James, 1996, “Growth Trends, Cyclical Fluctuations, and Welfare with Non-Expected Utility Preferences,” Economic Letters 50: 387-392.

Reis, Ricardo, 2009, “The Time Series Properties of Aggregate Consumption: Implications for the Costs of Fluctuations," Journal of the European Economic Association 7: 722-753.

Ruhm, Christopher J., 1991, “Workers Permanently Scarred by Job Displacements?” American Economic Review 81: 319-324.

Storesletten, Kjetil, Chris I. Telmer, and Amir Yaron, 2001, “The Welfare Cost of Business Cycles Revisited: Finite Lives and Cyclical Variation in Idiosyncratic Risk," European Economic Review 45: 1311-1339, 2001.

Storesletten, Kjetil, Chris I. Telmer, and Amir Yaron, 2004, “Cyclical Dynamics in Idiosyncratic Labor Market Risk,” Journal of Political Economy 112: 695-717. 
Tallarini, Thomas D. Jr., 2000, “Risk-Sensitive Real Business Cycles,” Journal of Monetary Economics 45: 507-532.

Weil, Philippe, 1990, “Nonexpected Utility in Macroeconomics,” Quarterly Journal of Economics 105: 29-42. 
Model Fit and Parameter Estimates, January Tranche, 1982:Q1 to 2019:Q4

The table reports the parameter estimates and model fit for the baseline model over the quarterly sample period from 1982:Q1 to 2019:Q4. Asymptotic standard errors (Newey-West corrected using two lags) for the parameter estimates and the sample moments are reported in parentheses below. The GMM system consists of 18 moment restrictions (15 aggregate moments and the mean, variance, and third central moment of the cross-sectional distribution of household consumption growth) in 15 parameters. $E\left[r_{f}\right], \sigma\left(r_{f}\right)$, and $\mathrm{AC} 1\left(r_{f}\right)$ are the mean, standard deviation, and first-order autocorrelation of the risk free rate; $E\left[r_{m}\right], \sigma\left(r_{m}\right)$, and $\operatorname{AC} 1\left(r_{m}\right)$ are the mean, standard deviation, and first-order autocorrelation of the market return; $E[p / d], \sigma(p / d)$, and $\operatorname{AC} 1(p / d)$ are the mean, standard deviation, and firstorder autocorrelation of the price-dividend ratio; $\Delta c$ is aggregate consumption growth; $\Delta d$ is aggregate dividend growth; $\mu_{2}^{1 / 2}\left(\Delta c_{C E X}\right)$ and $\mu_{3}\left(\Delta c_{C E X}\right)$ are the dispersion and third central moment of the cross-sectional distribution of household consumption growth. The preference parameters are the RRA coefficient, $\gamma$, the EIS, $\psi$, and the subjective discount factor, $\delta$. The rest of the parameters are defined in the text.

\begin{tabular}{|c|c|c|c|c|c|c|c|c|c|}
\hline \multicolumn{10}{|c|}{ Prices } \\
\hline & $E\left[r_{f}\right]$ & $\sigma\left(r_{f}\right)$ & $A C 1\left(r_{f}\right)$ & $E\left[r_{m}\right]$ & $\sigma\left(r_{m}\right)$ & $A C 1\left(r_{m}\right)$ & $E[p / d]$ & $\sigma(p / d)$ & $A C 1(p / d)$ \\
\hline Data & $\begin{array}{c}0.001 \\
(0.001)\end{array}$ & $\begin{array}{c}0.004 \\
(0.0003)\end{array}$ & $\begin{array}{c}0.722 \\
(0.101)\end{array}$ & $\begin{array}{c}0.019 \\
(0.007)\end{array}$ & $\begin{array}{c}0.084 \\
(0.007)\end{array}$ & $\begin{array}{c}-0.030 \\
(0.182)\end{array}$ & $\begin{array}{c}3.803 \\
(0.047)\end{array}$ & $\begin{array}{c}0.326 \\
(0.029)\end{array}$ & $\begin{array}{c}0.944 \\
(0.025)\end{array}$ \\
\hline
\end{tabular}

\begin{tabular}{ccccccccc}
\hline \multicolumn{1}{c}{ Consumption and Dividends } \\
\hline Data & $E[\Delta c]$ & $\sigma(\Delta c)$ & $A C 1(\Delta c)$ & $E[\Delta d]$ & $\sigma(\Delta d)$ & $A C 1(\Delta d)$ & $\mu_{2}^{1 / 2}\left(\Delta c_{C E X}\right)$ & $\mu_{3}\left(\Delta c_{C E X}\right)$ \\
& 0.004 & 0.009 & 0.138 & 0.012 & 0.110 & -0.639 & 0.404 & -0.039 \\
Model & $(0.001)$ & $(0.001)$ & $(0.183)$ & $(0.006)$ & $(0.014)$ & $(0.255)$ & $(0.004)$ & $(0.002)$ \\
& 0.004 & 0.009 & 0.000 & 0.005 & 0.080 & 0.000 & 0.378 & -0.042
\end{tabular}

\begin{tabular}{ccc}
\multicolumn{4}{c}{} \\
\hline$\gamma$ & Preference Parameters & $\delta$ \\
1.00 & $\psi$ & 0.861 \\
$(0.012)$ & $(0.0033)$ & $(0.003)$
\end{tabular}

\begin{tabular}{|c|c|c|c|c|c|c|c|c|c|c|c|}
\hline \multicolumn{12}{|c|}{ Other Parameters } \\
\hline $\begin{array}{c}0.004 \\
(0.001)\end{array}$ & $\begin{array}{c}0.017 \\
(0.154) \\
\end{array}$ & $\begin{array}{c}0.009 \\
(0.000) \\
\end{array}$ & $\begin{array}{c}0.00001 \\
(0.00001)\end{array}$ & $\begin{array}{c}0.003 \\
(0.010) \\
\end{array}$ & $\begin{array}{c}0.855 \\
(0.010) \\
\end{array}$ & $\begin{array}{c}0.839 \\
(0.079) \\
\end{array}$ & $\begin{array}{c}0.005 \\
(0.008) \\
\end{array}$ & $\begin{array}{c}0.080 \\
(0.004)\end{array}$ & $\begin{array}{c}-49.4 \\
(0.118) \\
\end{array}$ & $\begin{array}{c}0.800 \\
(0.097) \\
\end{array}$ & $\begin{array}{r}0.395 \\
(0.025) \\
\end{array}$ \\
\hline
\end{tabular}


TABLE 2

\section{Model Fit and Parameter Estimates, Annual Data, 1929 to 2019}

The table reports the parameter estimates and model fit with annual data over the sample period from 1929 to 2019. Asymptotic standard errors (Newey-West corrected using two lags) for the parameter estimates and the sample moments are reported in parentheses below. The GMM system consists of 15 moment restrictions in 15 parameters. $E\left[r_{f}\right], \sigma\left(r_{f}\right)$, and $\operatorname{AC} 1\left(r_{f}\right)$ are the mean, standard deviation, and first-order autocorrelation of the risk free rate; $E\left[r_{m}\right], \sigma\left(r_{m}\right)$, and $\operatorname{AC} 1\left(r_{m}\right)$ are the mean, standard deviation, and first-order autocorrelation of the market return; $E[p / d], \sigma(p / d)$, and $\operatorname{AC} 1(p / d)$ are the mean, standard deviation, and first-order autocorrelation of the pricedividend ratio; $\Delta c$ is aggregate consumption growth; $\Delta d$ is aggregate dividend growth. The preference parameters are the RRA coefficient, $\gamma$, the EIS, $\psi$, and the subjective discount factor, $\delta$. The rest of the parameters are defined in the text.

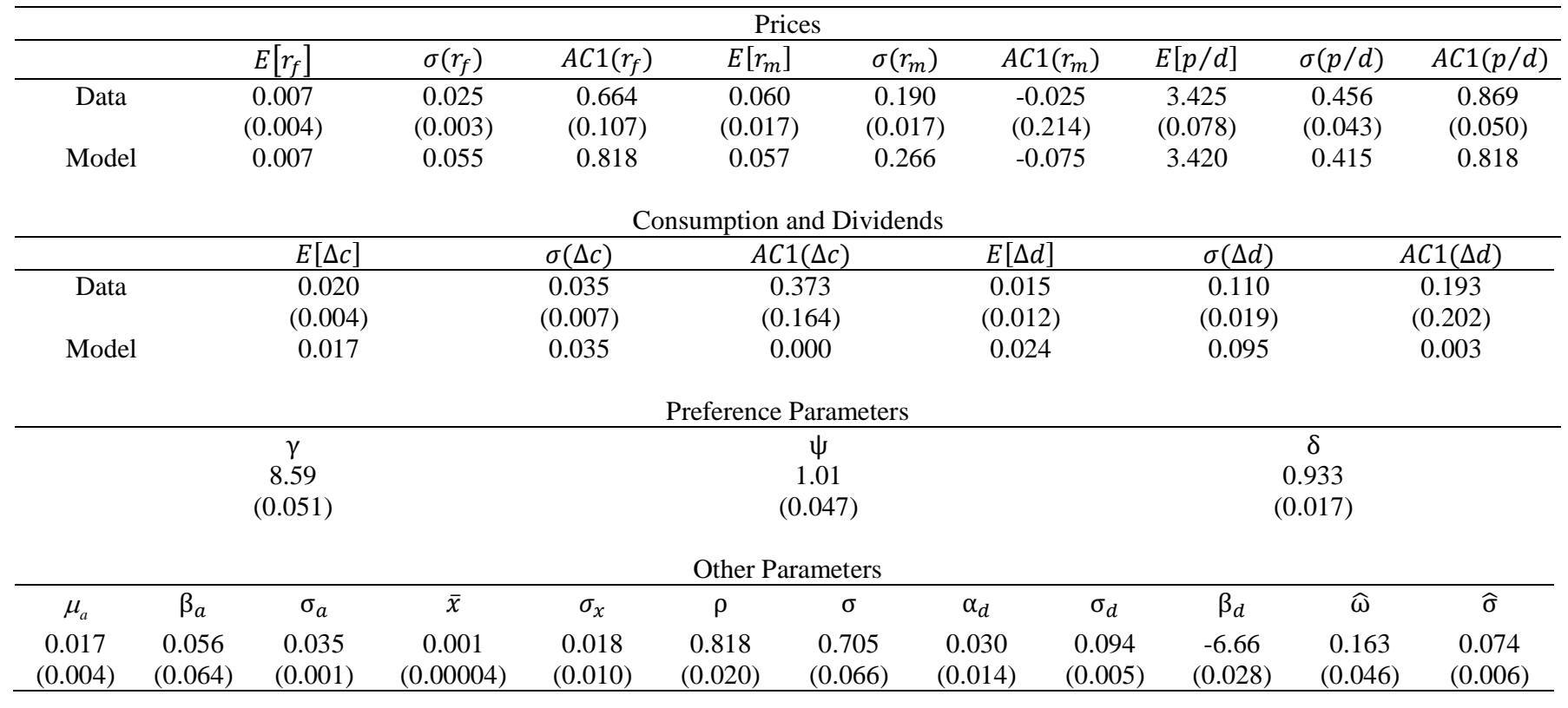




\section{TABLE 3 \\ Welfare Gains}

The table presents the welfare gain in percent relative to the benchmark economy, $\left(U^{N E W} / U^{B E N C H}-1\right) \times 100 \%$, by eliminating all idiosyncratic shocks to consumption growth, eliminating idiosyncratic shocks to consumption growth unrelated to the business cycle, eliminating idiosyncratic shocks to consumption growth related to the business cycle, eliminating shocks to aggregate consumption growth related to the business cycle, and eliminating shocks to aggregate consumption growth around trend. The calibration uses the parameters estimated with quarterly data from 1982:Q1 to 2019:Q4 from the January tranche and the combined tranches. The calibration also uses the parameters estimated with annual data from 1929 to 2019. I report the welfare gain when the current state is at its unconditional value and, in parentheses, when the state variable is set at the unconditional value plus or minus one standard error. In square brackets, I report the welfare gain when the volatility $\hat{\sigma}$ is set at the point estimate plus or minus one standard error.

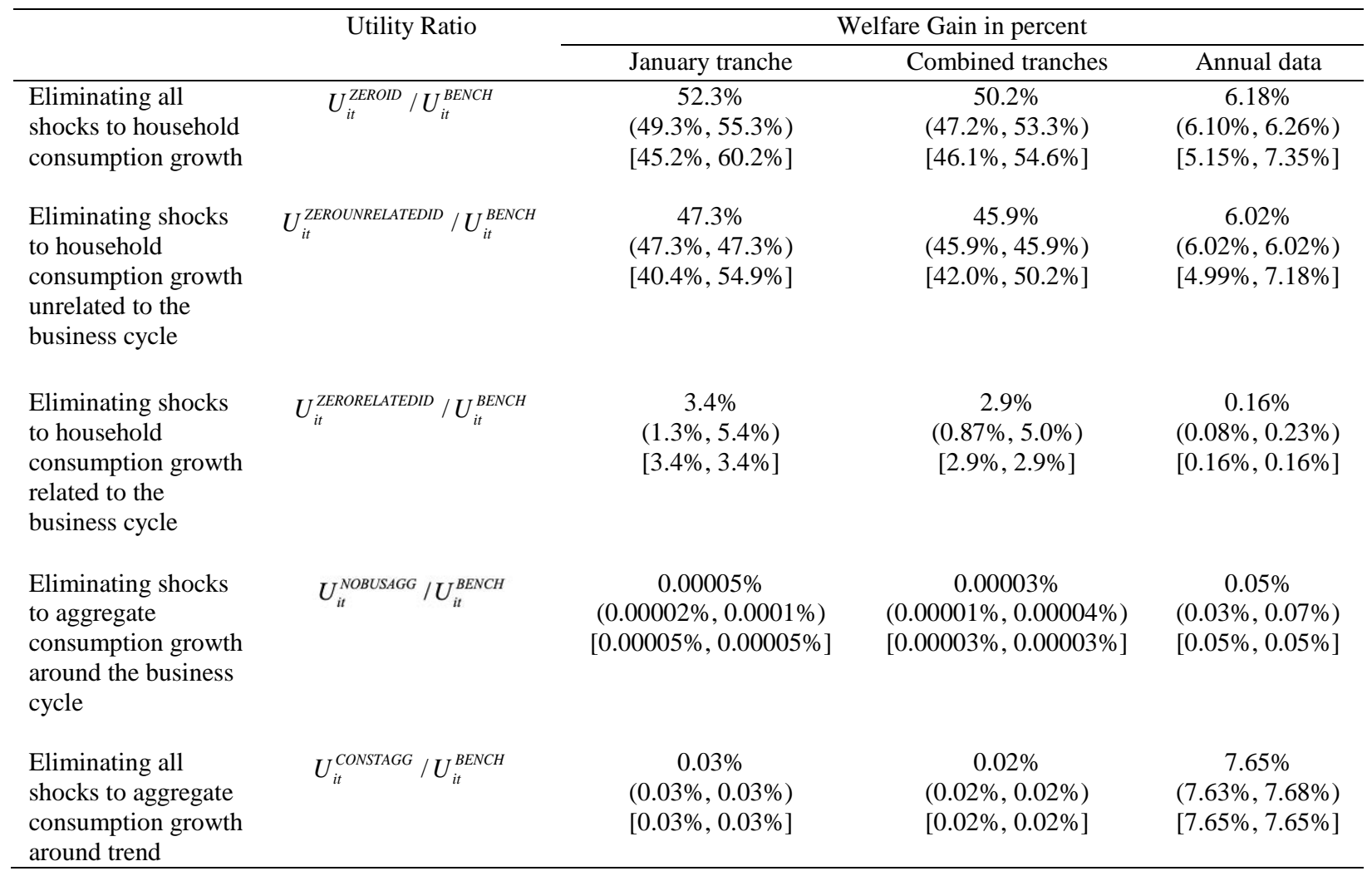




\section{TABLE 4}

\section{Variance and Skewness of Idiosyncratic and Aggregate Consumption Shocks}

The table presents the variance and skewness of idiosyncratic and aggregate consumption shocks. The model is calibrated with the parameters estimated with quarterly data from 1982:Q1 to 2009:Q4 and with annual data from 1929 to 2009. The state variable $\omega_{t+1}$ is set at its unconditional value and, in parentheses, equal to the unconditional value minus or plus one standard error.

\begin{tabular}{|c|c|c|c|}
\hline & $\begin{array}{l}\text { With parameter } \\
\text { estimates from the } \\
\text { January tranche }\end{array}$ & $\begin{array}{l}\text { With parameter } \\
\text { estimates from the } \\
\text { combined tranches }\end{array}$ & $\begin{array}{l}\text { With parameter } \\
\text { estimates from } \\
\text { annual data }\end{array}$ \\
\hline $\begin{array}{l}\text { Variance of idiosyncratic shocks } \\
\left(\sigma^{2}+\sigma^{4} / 4\right) \omega_{t+1}+\left(\hat{\sigma}^{2}+\hat{\sigma}^{4} / 4\right) \widehat{\omega}\end{array}$ & $\begin{array}{c}\mathbf{0 . 1 4 2 2} \\
(0.1347,0.1498)\end{array}$ & $\begin{array}{c}\mathbf{0 . 1 6 2 6} \\
(0.1536,0.1716)\end{array}$ & $\begin{array}{c}\mathbf{0 . 0 0 0 9} \\
(0.0009,0.0009)\end{array}$ \\
\hline $\begin{array}{l}\left(\sigma^{2}+\sigma^{4} / 4\right) \omega_{t+1} \\
\left(\hat{\sigma}^{2}+\hat{\sigma}^{4} / 4\right) \hat{\omega}\end{array}$ & $\begin{array}{c}0.0125 \\
(0.0050,0.0201) \\
0.1297\end{array}$ & $\begin{array}{c}0.0128 \\
(0.0038,0.0218) \\
0.1498\end{array}$ & $\begin{array}{c}0.0000 \\
(0.0000,0.0000) \\
0.0009 \\
(0.0009,0.0009)\end{array}$ \\
\hline $\begin{array}{c}\text { Skewness of idiosyncratic shocks } \\
-\left(3 \sigma^{4} / 2+\sigma^{6} / 8\right) \omega_{t+1}-\left(3 \hat{\sigma}^{4} / 2+\hat{\sigma}^{6} / 8\right) \hat{\omega}\end{array}$ & $\begin{array}{c}\mathbf{- 0 . 0 4 1 5} \\
(-0.0344,-0.0487)\end{array}$ & $\begin{array}{c}\mathbf{- 0 . 0 7 0 0} \\
(-0.0607,-0.0794)\end{array}$ & $\begin{array}{c}\mathbf{- 0 . 0 0 0 0 1} \\
(-0.00001,-0.00001)\end{array}$ \\
\hline $\begin{array}{l}-\left(3 \sigma^{4} / 2+\sigma^{6} / 8\right) \omega_{t+1} \\
-\left(3 \hat{\sigma}^{4} / 2+\hat{\sigma}^{6} / 8\right) \hat{\omega}\end{array}$ & $\begin{array}{c}-0.0119 \\
(-0.0048,-0.0191) \\
-0.0296\end{array}$ & $\begin{array}{c}-0.0133 \\
(-0.0040,-0.0227) \\
-0.0567\end{array}$ & $\begin{array}{c}-0.0000 \\
(-0.0000,-0.0000) \\
-0.00001\end{array}$ \\
\hline Variance of aggregate shocks & 0.00008 & 0.00008 & 0.00123 \\
\hline
\end{tabular}




\section{ONLINE APPENDIX A}

The unconditional mean, variance, and first-order autocorrelation of aggregate consumption growth:

$$
\begin{gathered}
E\left[\Delta c_{t}\right]=\mu_{a}, \\
\operatorname{var}\left(\Delta c_{t}\right)=\beta_{a}^{2} \bar{x} \sigma_{x}^{2} /\left(1-\rho^{2}\right)+\sigma_{a}^{2}, \text { and } \\
\operatorname{corr}\left(\Delta c_{t}, \Delta c_{t+1}\right)=\frac{\beta_{a}^{2} \rho}{\beta_{a}^{2}+\left(1-\rho^{2}\right) \sigma_{a}^{2} / \bar{x} \sigma_{x}^{2}}
\end{gathered}
$$

The unconditional mean, variance, and first-order autocorrelation of the risk free rate:

$$
\begin{gathered}
E\left[r_{t}\right]=-\theta \log \delta-\hat{\omega}\left(e^{\gamma(\gamma+1) \hat{\sigma}^{2} / 2}-1\right)+\gamma \mu_{a}-\gamma^{2} \sigma_{a}^{2} / 2+\left[-\lambda-\lambda^{2} \sigma_{x}^{2} / 2+(\theta-1) A_{1}\right] \bar{x}-(\theta-1)\left(h_{0}+h_{1} A_{0}-A_{0}\right), \\
\operatorname{var}\left(r_{t}\right)=\left(-\lambda \rho-\lambda^{2} \sigma_{x}^{2} / 2+(\theta-1) A_{1}+\beta_{a} \gamma\right)^{2} \bar{x} \sigma_{x}^{2} /\left(1-\rho^{2}\right), \text { and } \\
\operatorname{corr}\left(r_{t}, r_{t+1}\right)=\rho .
\end{gathered}
$$

The unconditional mean, variance, and first-order autocorrelation of the market return:

$$
\begin{gathered}
E\left[r_{m, t}\right]=k_{0}+\left(k_{1}-1\right)\left(B_{0}+B_{1} \bar{x}\right)+\alpha_{d}+\beta_{d} \bar{x} \\
\operatorname{var}\left(r_{m, t}\right)=\left[\left(k_{1} B_{1}\right)^{2}+\left(-B_{1}+\beta_{d}\right)^{2}+2\left(k_{1} B_{1}\right)\left(-B_{1}+\beta_{d}\right) \rho\right] \bar{x} \sigma_{x}^{2} /\left(1-\rho^{2}\right)+\sigma_{d}^{2}, \text { and } \\
\operatorname{corr}\left(r_{m, t}, r_{m, t+1}\right)=\frac{\left[\rho\left\{\left(k_{1} B_{1}\right)^{2}+\left(-B_{1}+\beta_{d}\right)^{2}\right\}+k_{1} B_{1}\left(-B_{1}+\beta_{d}\right)+\rho^{2} k_{1} B_{1}\left(-B_{1}+\beta_{d}\right)\right] \bar{x} \sigma_{x}^{2}}{\left[\left(k_{1} B_{1}\right)^{2}+\left(-B_{1}+\beta_{d}\right)^{2}+2\left(k_{1} B_{1}\right)\left(-B_{1}+\beta_{d}\right) \rho\right] \bar{x} \sigma_{x}^{2}+\left(1-\rho^{2}\right) \sigma_{d}^{2}} .
\end{gathered}
$$

The unconditional mean, variance, and first-order autocorrelation of the price-dividend ratio:

$$
\begin{gathered}
E\left[z_{m, t}\right]=B_{0}+B_{1} \bar{x}, \\
\operatorname{var}\left(z_{m, t}\right)=B_{1}^{2} \bar{x} \sigma_{x}^{2} /\left(1-\rho^{2}\right), \text { and } \\
\operatorname{corr}\left(z_{m, t}, z_{m, t+1}\right)=\rho .
\end{gathered}
$$

The unconditional mean, variance, and first-order autocorrelation of dividend growth:

$$
E\left[\Delta d_{t}\right]=\alpha_{d}+\beta_{d} \bar{x},
$$




$$
\begin{gathered}
\operatorname{var}\left(\Delta d_{t}\right)=\beta_{d}^{2} \bar{x} \sigma_{x}^{2} /\left(1-\rho^{2}\right)+\sigma_{d}^{2}, \text { and } \\
\operatorname{corr}\left(\Delta d_{t}, \Delta d_{t+1}\right)=\frac{\beta_{d}^{2} \rho}{\beta_{d}^{2}+\left(1-\rho^{2}\right) \sigma_{d}^{2} / \bar{x} \sigma_{x}^{2}} .
\end{gathered}
$$




\section{ONLINE APPENDIX B}

\section{B.1 Benchmark utility}

I rewrite the utility with unit elasticity, $\psi=1$, as

$$
U_{i t} / C_{i t}=\left\{E_{t}\left[\left(U_{i, t+1} / C_{i, t+1}\right)^{1-\gamma}\left(C_{i, t+1} / C_{i t}\right)^{1-\gamma}\right]\right\}^{\frac{\delta}{1-\gamma}} .
$$

I conjecture and verify that $U_{i t} / C_{i, t}=e^{h+k x_{t}}$ where $h$ and $k$ are parameters. Then

$$
\begin{array}{r}
e^{h+k x_{t}}=\left(E_{t}\left[e^{(1-\gamma)\left(h+k x_{t+1}\right)+(1-\gamma) \Delta c_{i, t+1}}\right]\right)^{\frac{\delta}{1-\gamma}} \text {, or } \\
e^{\frac{1-\gamma}{\delta}\left(h+k x_{t}\right)}=E_{t}\left[e^{(1-\gamma)\left(h+k x_{t+1}\right)+(1-\gamma) \Delta c_{i, t+1}}\right] .
\end{array}
$$

First, I integrate out the random variables $\eta_{i, t+1}$ and $\hat{\eta}_{i, t+1}$, which are i.i.d. standard normal and independent of all primitive random variables in the economy and obtain

$$
\begin{aligned}
& E_{t}\left[e^{(1-\gamma)\left(h+k_{t+1}\right)+(1-\gamma) \Delta c_{i, t+1}}\right] \\
& =E_{t}\left[e^{(1-\gamma) h+(1-\gamma) k x_{t+1}+(1-\gamma)\left(\mu_{a}+\beta_{a}\left(x_{t}-\bar{x}\right)+\sigma_{a} \varepsilon_{a, t+1}\right)+(1-\gamma)\left(j_{i, t+1}^{1 / 2} \sigma \eta_{i, t+1}-j_{i, t+1} \sigma^{2} / 2+\hat{j}_{i, t+1}^{1 / 2} \hat{\sigma} \hat{\eta}_{i, t+1}-\hat{j}_{i, t+1} \hat{\sigma}^{2} / 2\right)}\right] \\
& =E_{t}\left[e^{(1-\gamma) h+(1-\gamma) k x_{t+1}+(1-\gamma)\left(\mu_{a}+\beta_{a}\left(x_{t}-\bar{x}\right)+\sigma_{a} \varepsilon_{a, t+1}\right)-\gamma(1-\gamma) \sigma^{2} j_{i, t+1} / 2-\gamma(1-\gamma) \hat{\sigma}^{2} \hat{j}_{i, t+1} / 2}\right] .
\end{aligned}
$$

Second, I use the result that, for any constant $b$,

$$
E\left[e^{b j}\right]=e^{-\omega} \sum_{n=0}^{\infty} e^{b n} \omega^{n} / n !=e^{-\omega} \sum_{n=0}^{\infty}\left(e^{b} \omega\right)^{n} / n !=e^{-\omega} e^{e^{b} \omega},
$$

integrate out the random variables $j_{i, t+1}$ and $\hat{j}_{i, t+1}$, and obtain

$$
\begin{aligned}
& E_{t}\left[e^{(1-\gamma) h+(1-\gamma) k x_{t+1}+(1-\gamma)\left(\mu_{a}+\beta_{a}\left(x_{t}-\bar{x}\right)+\sigma_{a} \varepsilon_{a, t+1}\right)-\gamma(1-\gamma) \sigma^{2} j_{i, t+1} / 2-\gamma(1-\gamma) \hat{\sigma}^{2} \hat{j}_{i, t+1} / 2}\right] \\
& =E_{t}\left[e^{(1-\gamma) h+(1-\gamma) k x_{t+1}+(1-\gamma)\left(\mu_{a}+\beta_{a}\left(x_{t}-\bar{x}\right)+\sigma_{a} \varepsilon_{a, t+1}\right)-\omega_{t+1}+\omega_{t+1} e^{-\gamma(1-\gamma) \sigma^{2} / 2}-\hat{\omega}+\hat{\omega} \hat{e}^{-\gamma(1-\gamma) \hat{\sigma}^{2} / 2}}\right] \\
& =E_{t}\left[e^{(1-\gamma) h+\hat{x}+\{(1-\gamma) k+1\} x_{t+1}+(1-\gamma)\left(\mu_{a}+\beta_{a}\left(x_{t}-\bar{x}\right)+\sigma_{a} \varepsilon_{a, t+1}\right)}\right],
\end{aligned}
$$


where I define $x_{t} \equiv\left(e^{-\gamma(1-\gamma) \sigma^{2} / 2}-1\right) \omega_{t}$ and $\hat{x} \equiv\left(e^{-\gamma(1-\gamma) \hat{\sigma}^{2} / 2}-1\right) \hat{\omega}$. Third, I integrate out $\varepsilon_{x, t+1}$ and $\varepsilon_{a, t+1}$ and obtain

$$
\begin{aligned}
& E_{t}\left[e^{(1-\gamma) h+\hat{x}+\{(1-\gamma) k+1\} x_{t+1}+(1-\gamma)\left(\mu_{a}+\beta_{a}\left(x_{t}-\bar{x}\right)+\sigma_{a} \varepsilon_{a, t+1}\right)}\right] \\
& =e^{(1-\gamma) h+\hat{x}+\{(1-\gamma) k+1\}\left\{(1-\rho) \bar{x}+\rho x_{t}\right\}+\{(1-\gamma) k+1\}^{2} x_{t} \sigma_{x}^{2} / 2+(1-\gamma)\left(\mu_{a}+\beta_{a}\left(x_{t}-\bar{x}\right)\right)+(1-\gamma)^{2} \sigma_{a}^{2} / 2} .
\end{aligned}
$$

Therefore,

$$
h+k x_{t}=\frac{\delta}{1-\gamma}\left\{\begin{array}{l}
(1-\gamma)\left(\mu_{a}+\beta_{a}\left(x_{t}-\bar{x}\right)\right)+(1-\gamma)^{2} \sigma_{a}^{2} / 2+\{(1-\gamma) k+1\}\left((1-\rho) \bar{x}+\rho x_{t}\right) \\
+\{(1-\gamma) k+1\}^{2} x_{t} \sigma_{x}^{2} / 2+\hat{x}+(1-\gamma) h
\end{array}\right\} .
$$

The conjecture $U_{i t} / C_{i, t}=e^{h+k x_{t}}$ is verified. I obtain the values of the parameters $h$ and $k$ by matching the constants and the coefficients of $x_{t}$ in the above equation and obtain

$$
h=\frac{\hat{x}+\{(1-\gamma) k+1\}(1-\rho) \bar{x}+(1-\gamma)\left(\mu_{a}-\beta_{a} \bar{x}\right)+(1-\gamma)^{2} \sigma_{a}^{2} / 2}{(1-\gamma)\left(\delta^{-1}-1\right)}
$$

and

$$
(1-\gamma)^{2}\left(\sigma_{x}^{2} / 2\right) k^{2}+\left\{\sigma_{x}^{2}+\rho-\delta^{-1}\right\}(1-\gamma) k+(1-\gamma) \beta_{a}+\rho+\sigma_{x}^{2} / 2=0
$$

The solution to the above equation is

$$
k=\frac{-\left(\rho+\sigma_{x}^{2}-\delta^{-1}\right)}{(1-\gamma) \sigma_{x}^{2}}\left[1-\sqrt{1-\frac{2 \sigma_{x}^{2}\left((1-\gamma) \beta_{a}+\rho+\sigma_{x}^{2} / 2\right)}{\left(\rho+\sigma_{x}^{2}-\delta^{-1}\right)^{2}}}\right]
$$

I retain the solution with the negative square root because the solution with the positive square root tends to $-\infty$ as $\sigma_{x}^{2} \rightarrow 0$.

\section{B.2 Utility with general elasticity, $\psi \neq 1$}

I rewrite the utility with elasticity $\psi \neq 1$ as 


$$
\begin{gathered}
U_{i t} / C_{i t}=\left\{(1-\delta)+\delta\left(E_{t}\left[\left(\frac{C_{i, t+1}}{C_{i t}} \frac{U_{i, t+1}}{C_{i, t+1}}\right)^{1-\gamma}\right]\right)^{\frac{1-1 / \psi}{1-\gamma}}\right\}^{1 /(1-1 / \psi)}, \text { or } \\
\left(\frac{U_{i t}}{C_{i t}}\right)^{(1-1 / \psi)}=1-\delta+\delta\left(E_{t}\left[\left(\frac{C_{i, t+1}}{C_{i t}}\right)^{1-\gamma}\left(\frac{U_{i, t+1}}{C_{i, t+1}}\right)^{1-\gamma}\right]\right)^{\frac{1-1 / \psi}{1-\gamma}}
\end{gathered}
$$

and conjecture that $U_{i t} / C_{i, t}=e^{h+k x_{t}}$. Then

$$
\begin{aligned}
& e^{(1-1 / \psi)\left(h+k x_{t}\right)}-1+\delta=\delta\left\{E\left[e^{(1-\gamma)\left(\mu_{a}+\beta_{a}\left(x_{t}-\bar{x}\right)+\sigma_{a} \varepsilon_{a, t+1}\right)+(1-\gamma)\left(j_{i, t+1}^{1 / 2} \sigma \eta_{i, t+1}-j_{i, t+1} \sigma^{2} / 2+\hat{j_{i, t+1}} \hat{\sigma} \hat{\eta}_{i, t+1} \hat{j}_{i, t+1} \hat{\sigma}^{2} / 2\right)+(1-\gamma)\left(h+k x_{t+1}\right)}\right]\right\}^{\frac{1-1 / \psi}{1-\gamma}} \\
& \left.\left.=\delta\left\{E\left[e^{(1-\gamma)\left(\mu_{a}+\beta_{a}\left(x_{t}-\bar{x}\right)+\sigma_{a} \varepsilon_{a, t+1}\right)-\gamma(1-\gamma) \sigma^{2} j_{i, t+1} / 2-\gamma(1-\gamma) \hat{\sigma}^{2} \hat{j}_{i, t+1} / 2+(1-\gamma)\left(h+k x_{t+1}\right)}\right]\right\}^{\frac{1-1 / \psi}{1-\gamma}}\right]\right\}^{\frac{1-1 / \psi}{1-\gamma}} \\
& \left.\left.=\delta\left\{E\left[e^{(1-\gamma)\left(\mu_{a}+\beta_{a}\left(x_{t}-\bar{x}\right)+\sigma_{a} \varepsilon_{a, t+1}\right)-\omega_{t+1}+\omega_{t+1} e^{-\gamma(1-\gamma) \sigma^{2} / 2}-\hat{\omega}+\hat{\omega} e^{-\gamma(1-\gamma) \hat{\sigma}^{2} / 2}+(1-\gamma)\left(h+k x_{t+1}\right)}\right]\right\}^{\frac{1-1 / \psi}{1-\gamma}}\right]\right\}^{\frac{1-1 / \psi}{1-\gamma}} .
\end{aligned}
$$

With the approximation $e^{z} \approx 1+z$, I obtain

$$
\begin{aligned}
& 1+(1-1 / \psi)\left(h+k x_{t}\right)-1+\delta \\
& =\delta+\delta \frac{1-1 / \psi}{1-\gamma}\left\{\begin{array}{l}
(1-\gamma)\left(\mu_{a}+\beta_{a}\left(x_{t}-\bar{x}\right)\right)+(1-\gamma)^{2} \sigma_{a}^{2} / 2 \\
+\{(1-\gamma) k+1\}\left((1-\rho) \bar{x}+\rho x_{t}\right)+\{(1-\gamma) k+1\}^{2} x_{t} \sigma_{x}^{2} / 2+\hat{x}+(1-\gamma) h
\end{array}\right\}
\end{aligned}
$$

or

$$
h+k x_{t}=\frac{\delta}{1-\gamma}\left\{\begin{array}{l}
(1-\gamma)\left(\mu_{a}+\beta_{a}\left(x_{t}-\bar{x}\right)\right)+(1-\gamma)^{2} \sigma_{a}^{2} / 2 \\
+\{(1-\gamma) k+1\}\left((1-\rho) \bar{x}+\rho x_{t}\right)+\{(1-\gamma) k+1\}^{2} x_{t} \sigma_{x}^{2} / 2+\hat{x}+(1-\gamma) h
\end{array}\right\}
$$

which is identical to equation (B6). 


\section{B.3 Utility without all or some idiosyncratic consumption shocks}

I compare the economy in which idiosyncratic consumption shocks are eliminated to the benchmark economy. I refer to this economy as ZEROID. Without idiosyncratic consumption shocks, I set $\sigma=\hat{\sigma}=0$. Then $x_{t}=\bar{x}=0$ and

$$
U_{i t}^{\text {ZEROID }} / U_{i t}^{\text {BENCH }}=\exp \left(\frac{-\hat{x}-\{(1-\gamma) k+1\}(1-\rho) \bar{x}+(1-\gamma) \beta_{a} \bar{x}}{(1-\gamma)\left(\delta^{-1}-1\right)}-k x_{t}\right) .
$$

Second, I compare the benchmark economy to the economy in which idiosyncratic consumption shocks unrelated to the business cycle are eliminated. I refer to this economy as ZEROUNRELATEDID. I eliminate these shocks by setting $\hat{\sigma}=0$ and this implies $\hat{x}=0$. I set $\hat{x}=0$ and obtain

$$
U_{i t}^{\text {ZEROUNRELATEDID }} / U_{i t}^{\text {BENCH }}=e^{-\widehat{x}(1-\gamma)\left(\delta^{-1}-1\right)} .
$$

Third, I compare the benchmark economy to the economy in which idiosyncratic consumption shocks related to the business cycle are eliminated. I refer to this economy as ZERORELATEDID. I eliminate these shocks by setting $\sigma=0$ and this implies $x_{t}=\bar{x}=0$. Then

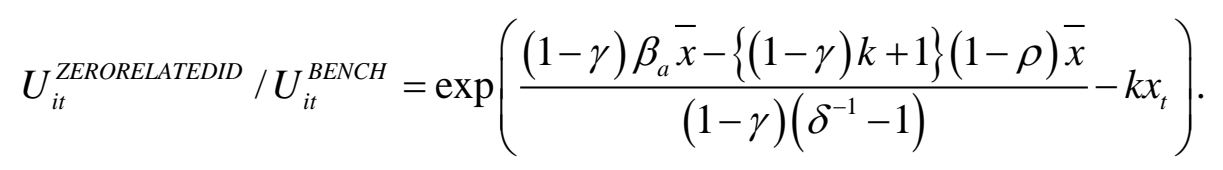

\section{B.4 Utility without fluctuations of aggregate consumption growth}

In eliminating fluctuations of aggregate consumption growth around the business cycle, I set $\beta_{a}=0$ and replace $\mu_{a}$ with $\mu_{a}+\beta_{a}^{2} \bar{x} \sigma_{x}^{2} / 2\left(1-\rho^{2}\right)$ so that $E\left[C_{t+1} / C_{t}\right]=e^{\mu_{a}+\beta_{a}^{2} \bar{x} \sigma_{x}^{2} / 2\left(1-\rho^{2}\right)+\sigma_{a}^{2} / 2}$, as in the benchmark case. The utility ratio is 


$$
\begin{aligned}
& U_{i t}^{\text {NOBUSAGG }} / U_{i t}^{\text {BENCH }} \\
& =\exp \left\{\frac{\beta_{a} \bar{x}}{\delta^{-1}-1}+\frac{\left(\rho+\sigma_{x}^{2}-\delta^{-1}\right)}{(1-\gamma) \sigma_{x}^{2}}\left[\sqrt{1-\frac{2 \sigma_{x}^{2}\left(\rho+\sigma_{x}^{2} / 2\right)}{\left(\rho+\sigma_{x}^{2}-\delta^{-1}\right)^{2}}}-\sqrt{1-\frac{2 \sigma_{x}^{2}\left((1-\gamma) \beta_{a}+\rho+\sigma_{x}^{2} / 2\right)}{\left(\rho+\sigma_{x}^{2}-\delta^{-1}\right)^{2}}}\right] x_{t}\right\} .
\end{aligned}
$$

Finally, in eliminating all fluctuations of aggregate consumption growth around trend, I set $\beta_{a}=\sigma_{a}=0$ and replace $\mu_{a}$ with $\mu_{a}+\beta_{a}^{2} \bar{x} \sigma_{x}^{2} / 2\left(1-\rho^{2}\right)+\sigma_{a}^{2} / 2$ so that $E\left[C_{t+1} / C_{t}\right]=e^{\mu_{a}+\beta_{a}^{2} \bar{x} \sigma_{x}^{2} / 2\left(1-\rho^{2}\right)+\sigma_{a}^{2} / 2}$, as in the benchmark case. I refer to this economy as economy CONSTAGG. The ratio of the utility in this economy to the utility in the benchmark economy is

$$
U_{i t}^{\text {CONSTAGG }} / U_{i t}^{\text {BENCH }}=\exp \left(\begin{array}{l}
\frac{\beta_{a}^{2} \bar{x} \sigma_{x}^{2} / 2\left(1-\rho^{2}\right)+\beta_{a} \bar{x}+\gamma \sigma_{a}^{2} / 2}{\delta^{-1}-1} \\
\left.+\frac{\left(\rho+\sigma_{x}^{2}-\delta^{-1}\right)}{(1-\gamma) \sigma_{x}^{2}}\left[\sqrt{1-\frac{2 \sigma_{x}^{2}\left(\rho+\sigma_{x}^{2} / 2\right)}{\left(\rho+\sigma_{x}^{2}-\delta^{-1}\right)^{2}}}-\sqrt{1-\frac{2 \sigma_{x}^{2}\left((1-\gamma) \beta_{a}+\rho+\sigma_{x}^{2} / 2\right)}{\left(\rho+\sigma_{x}^{2}-\delta^{-1}\right)^{2}}}\right] x_{t}\right]
\end{array}\right.
$$




\section{ONLINE APPENDIX C}

\section{Model Fit and Parameter Estimates, Combined Tranches, 1982:Q1 to 2019:Q4}

The table reports the parameter estimates and model fit for the combined tranches over the quarterly sample period from 1982:Q1 to 2019:Q4. Asymptotic standard errors (Newey-West corrected using two lags) for the parameter estimates and the sample moments are reported in parentheses below. The GMM system consists of 18 moment restrictions (15 aggregate moments and the mean, variance, and third central moment of the cross-sectional distribution of household consumption growth) in 15 parameters. $E\left[r_{f}\right], \sigma\left(r_{f}\right)$, and $\operatorname{AC} 1\left(r_{f}\right)$ are the mean, standard deviation, and first-order autocorrelation of the risk free rate; $E\left[r_{m}\right], \sigma\left(r_{m}\right)$, and $\mathrm{AC} 1\left(r_{m}\right)$ are the mean, standard deviation, and first-order autocorrelation of the market return; $E[p / d], \sigma(p / d)$, and $\operatorname{AC} 1(p / d)$ are the mean, standard deviation, and first-order autocorrelation of the price-dividend ratio; $\Delta c$ is aggregate consumption growth; $\Delta d$ is aggregate dividend growth; $\mu_{2}^{1 / 2}\left(\Delta c_{C E X}\right)$ and $\mu_{3}\left(\Delta c_{C E X}\right)$ are the dispersion and third central moment of the cross-sectional distribution of household consumption growth. The preference parameters are the RRA coefficient, $\gamma$, the EIS, $\psi$, and the subjective discount factor, $\delta$. The rest of the parameters are defined in the text.

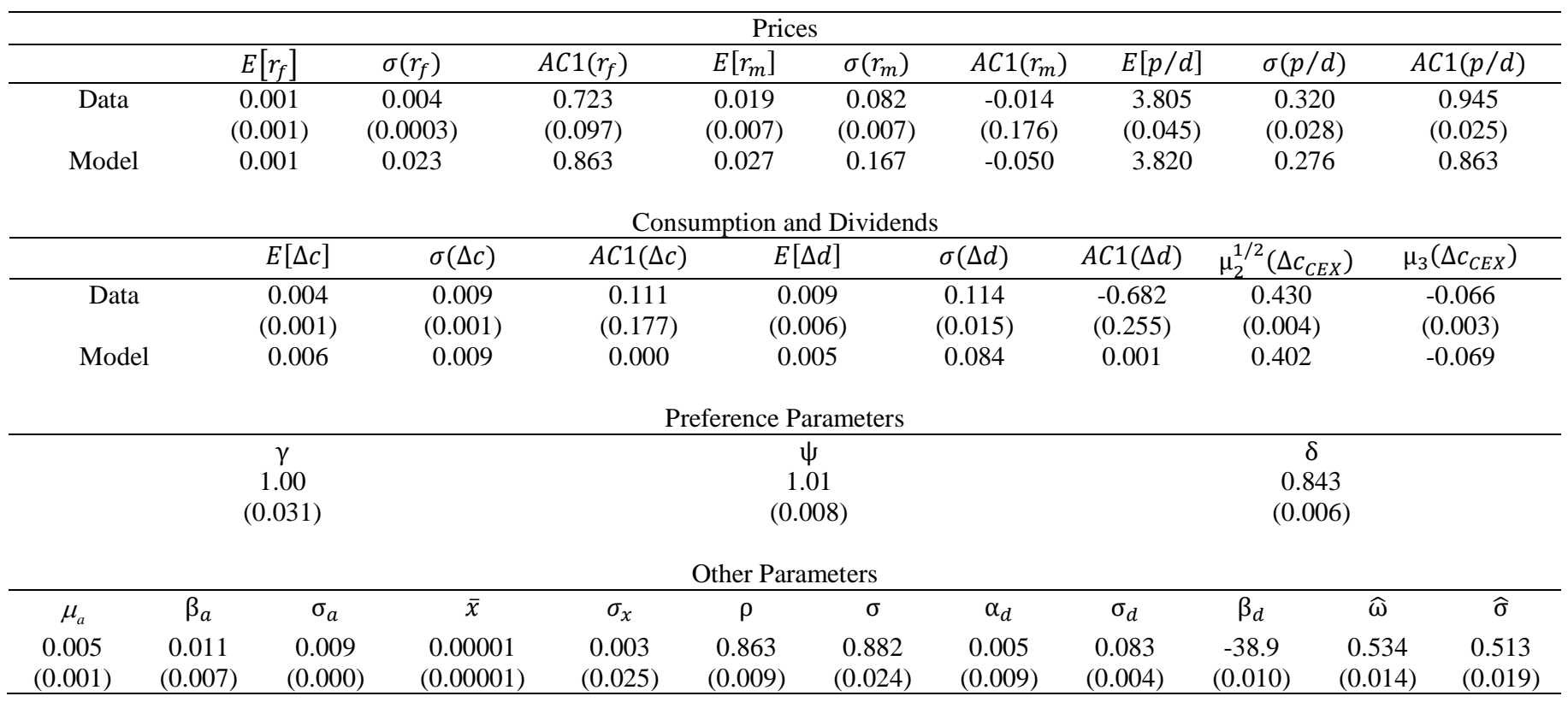

